\title{
monterrey y bilbao (1870-1914): empresariado, industria y desarrollo regional en la periferia'
}

\author{
Mario Cerutti \\ Universidad Autónoma de Nuevo León \\ Jesús María Valdaliso \\ Facultad de Ciencias Económicas y Empresariales, Universidad del País Vasco
}

\section{RESUMEN}

Bilbao (norte de España) y Monterrey (norte de México) acunaron un interesante ciclo de crecimiento fabril en las postrimerías del siglo XIX. Ambas ciudades se perfilaron como ejes de un crecimiento regional estimulado por demandas generadas tanto en economías que habían consumado la revolución industrial como por los respectivos mercados internos. El artículo presenta un sucinto cotejo de los procesos vividos en esas urbes y en su entorno geográfico entre 1870 y 1914 . Alude también a la aparición de ágiles grupos empresariales dedicados a la industria fabril, la minería y la banca, destaca la significación que asumió la metalurgia pesada, menciona la fluida absorción de tecnología proveniente de sociedades avanzadas y recuerda la trascendencia que tuvo la sociedad anónima para la transferencia de capitales a la producción en gran escala.

\begin{abstract}
Bilbao (Northern Spain) and Monterrey (Northern Mexico) gave birth to interesting cycles of industrial growth during the latenineteenth century. These two cities became centers of regional growth, spurred by demands generated both in countries that had already achieved industrial revolution, and in their domestic markets. This paper compares how Bilbao and Monterrey experienced this process between 1870 and 1914 , as well as describing the appearance of efficient entrepreneurial groups dedicated to the trading, manufacturing, banking and mining industries. It also mentions issues such as the importance acquired by heavy metallurgy, the swift adoption of technology from advanced societies and the relevance of anonymous societies in the large-scale transfer of capital for production.
\end{abstract}

\section{Introducción}

Aunque el tema es complejo y denso, no se pretende que este trabajo llegue demasiado lejos. Se trata, tan sólo, de un racimo de consideraciones iniciales, de un intento de cotejo entre procesos económico/empresariales de sesgos regionales suscitados en México y España en un período limitado: el que corrió desde 1870 a 1914.

Presentado en el XIII Congreso Internacional de Historia Económica (Buenos Aires,julio de 2002). 
Si hay algo que ha terminado de verificarse en algunas sociedades latinoamericanas que mostraban mayor desarrollo relativo a principios del siglo XX - México, por ejemplo - y algunas europeas incorporadas con retraso al proceso de industrialización - España, entre otras - es que aquel desarrollo nada tuvo de homogéneo a escala de cada Estadonación. Por el contrario, mostraban profundos desequilibrios que hoy son visibles - habrían de marcar la historia posterior.

Una mirada atenta, regionalizada, ${ }^{2}$ del siglo XIX insinúa lo fructífero que puede resultar de observar paralelamente ciertos fenómenos de las periferias europea y latinoamericana. ${ }^{3}$ Aunque, es verdad, se trataría de un planteamiento delicado. Para empezar significa una fuerte fractura con la muy asentada concepción de observar lo europeo como antagónico u opuesto a lo latinoamericano: una visión sensiblemente alentada por las nociones dependentistas que tan fulminante éxito obtuvieron desde fines de los años 60 en las Ciencias Sociales. Además, puede llevar no sólo a una controversia entre latinoamericanistas, sino también con colegas dedicados al siglo XIX en Europa.

Pero, ¿cuál Europa? ¿Sólo la de las economías líderes de la revolución industrial? ¿No hubo otra Europa menos conmovida por dicha ruptura histórica? ¿Y España? ¿Y Portugal? ¿Y esa misma Italia tan condicionada, atrapada por el feudalizado Sur? Como bien lo ha señalado Pollard, la revolución industrial no sólo habría sido un fenómeno fuertemente regional: además, no alcanzó a trastocar radicalmente - en el siglo pasado y hasta la Primera Guerra - todo el occidente europeo.Y la forma de proyectarse sobre su periferia más cercana - España, Portugal, por ejemplo - no parece haber sido excesivamente distinta a la que golpeó buena parte del continente americano. Si así fuere, se podría arriesgar finalmente otra incitante sugerencia: tal vez resulte más provechoso desde el punto de vista comparativo - enfrentar México con España que, verbigracia, hacerlo con Haití, Paraguay o Venezuela.

Si bien el marco del Estado-nación no puede estar ausente en la indagación sobre procesos decisivos en la formación del capitalismo, convendría descartar la tentación de ampliar a todo su contexto las especificidades de ciertos fenómenos regionales. Por otro lado, el cotejo exclusivo y excluyente entre espacios regionales de un mismo Estadonación no siempre resulta enriquecedor. La fertilidad del esfuerzo comparativo - ejercicio indispensable para el conocimiento histórico - quizá se multiplique si opera con espacios regionales pertenecientes a sociedades y estados nacionales diferentes.

Un intento a escala de formación de burguesías y brotes regionales de industrialización se encuentra en Cerutti y Vellinga (1989).

Pollard, 1991. 
España y México: ¿pueden cotejarse?

Un racimo de fenómenos y tendencias de visible paralelismo emergió en el devenir decimonónico mexicano y español. Para empezar, nada menos que la desamortización de bienes corporativos (eclesiásticos, municipales y, en México, de comunidades indígenas), y lo que los

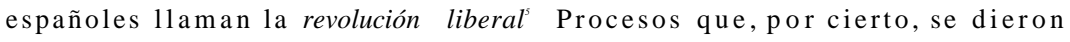
totalmente entrelazados y que apuntaron a modernizar - por medio de reformas - las estructuras socioeconómicas, institucionales y políticas de ambas sociedades.

Si de México y España se continúa hablando, hubo mucho más. Tras las respectivas guerras de independencia (en las que Españajugó los dos papeles) llegaría una prolongada inestabilidad política e institucional, las pugnas civiles y la influencia creciente del poder militar, el prolongado combate entre grupos liberales y unos conservadores aliados con frecuencia - a los jefes castrenses y avalados casi siempre por la iglesia católica, los aparatos estatales con déficits permanentes, las dificultades para consumar la revolución liberal y el final acuerdo (ya en las últimas décadas del siglo) entre conservadores modernizantes y liberales moderados.

No menos atractiva se presenta la revisión de ciertos datos de los dos sistemas nacionales de producción y sus vinculaciones con la economía mundial. El atraso rural, la importancia de la gran propiedad, los obstáculos para la configuración de un ágil mercado interior y para una dinámica generalización de los componentes capitalistas, el avance por momentos tortuosos de las políticas económicas de sesgo liberal, el impacto ocasionado por el tendido de los ferrocarriles y las inversiones extranjeras, la consolidación en la segunda mitad del siglo de áreas especializadas en la exportación de productos primarios, la aparición de focos de industrialización y - con ello - el tan desigual peso que asumieron ciertos espacios regionales dibujan, en síntesis, un cuadro riquísimo para el cotejo, para una simultánea indagación.

Y, además, algo que alude a puntos nucleares de este trabajo: los mecanismos que permitieron prosperar a segmentos empresariales regionales en las tan poco favorables condiciones de un siglo XIX tumultuoso, la conexión entre el mercado de los países avanzados y determinados brotes de industrialización, y el papel que jugaron ins-

Véase un intento comparativo en Menegus y Cerutti, en prensa. 
tituciones como la sociedad anónima, las redes familiares y la industria pesada en esos limitados pero diferenciables desarrollos regionales.

España y México - como la misma Italia - constituyeron casos llamativos de sociedades fundamentalmente agrarias que, a fines del XIX, se encontraban en la periferia más cercana, inmediata, de los centros de la revolución industrial. Si España se adhería a la frontera europea - Francia, ${ }^{6}$ Inglaterra, el mismo norte italiano - México se articulaba por el norte al mercado que crecía con los ritmos más impresionantes de la época: los Estados Unidos.' En las dos situaciones, ese escenario mayor que era la revolución industrial no dejó de provocar efectos peculiares: los medios de comunicación y transportes - el ferrocarril, el vapor, el telégrafo - vincularon áreas económicas y fronteras políticas antes deshilvanadas, y se gestaron enormes demandas de materias primas industriales e insumos derivados de la producción pesada (metalurgia básica).

Si bien México y España operaban desde la periferia, pudieron responder a través de sistemas regionales que lograron situarse en un escalón intermedio entre los parámetros de la sociedad capitalista contemporánea. Nivel que se expresó - entre otras variables - con la emergencia de empresariados de base fabril, de poderosos grupos económicos dispuestos a asociar sus capitales y a competir no sólo en el mercado interior: también, a disputar porciones del propio mercado internacional.

\section{Bilbao y Monterrey}

El motivo de este trabajo, pues, es ofrecer un rápido cotejo entre Bilbao, en el País Vasco, y el Monterrey del norte oriental mexicano. Se pondrá particular énfasis en la respectiva aparición de empresariados dedicados a la industria urbana, en la importancia que asumió la gran metalurgia, en el doble impacto de los mercados nacional e internacional y en la trascendencia que la sociedad anónima tuvo para la inserción de capitales en la producción a gran escala.

Bilbao y Monterrey iniciaron un interesante ciclo de crecimiento fabril en las postrimerías del siglo XIX. Los respectivos auges coincidieron con llamativas transformaciones en los mercados internos y con

Para la circunstancia catalana véase Maluquer de Motes, 2001.

"Desde los años setenta del siglo XIX (...) el mercado interior estadounidense creció más de prisa que el de cualquier otro país". Se trataba del "mercado interior más extenso y de crecimiento más rápido del mundo". Chandler, 1996, pp.82-83. 
marcadas demandas de insumos intermedios por parte de las economías avanzadas. A diferencia de Barcelona y su entorno, de Puebla y el valle central de México, o de Sao Paulo, no fueron las fábricas de bienes livianos y de consumo masivo el dato vertebral que caracterizó a Bilbao y Monterrey, sino la producción de bienes e insumos destinado a la misma producción. Si en Monterrey se fundaron grandes establecimientos de fundición productores de metales no ferrosos y ferrosos (a los que se agregaron fábricas de cemento y vidrio), en Bilbao fue creada una vigorosa industria siderúrgica, a la que siguieron empresas transformadoras del hierro y del acero, fábricas de papel y astilleros. En ambos casos - además de surgir plantas dedicadas a bienes de consumo masivo (cerveza y otras bebidas, alimentos, artículos de higiene) - los últimos años del XIX y los inaugurales del XX enmarcaron la apertura de instituciones bancarias.

¿Cómo pudieron protagonizarse estos procesos en sociedades en las que supuestamente los grupos empresariales eran tan débiles como incipientes, en las que estos núcleos podían verse sometidos a las políticas nacionales de sectores dominantes menos innovadores, y en las cuales el capital extranjero - según se ha solido narrar reiteradamente - predominaba con amplitud?

\section{El impacto del comercio}

Un elemento decisivo en ambos marcos regionales lo constituyó en las décadas anteriores al montaje de las grandes firmas industriales un verificable proceso de formación previa de capitales, de concentración de bienes y recursos. Los segmentos propietarios que al agotarse el XIX operaban desde Bilbao y Monterrey habían sabido experimentar con habilidad en un escenario saturado de crónicos desajustes sociopolíticos. No puede extrañar, por lo tanto, que una de las vías principales de acumulación fuese, en ambos centros urbanos, el comercio.

La actividad mercantil y naviera gozaba de una larga historia en el puerto de Bilbao.' Su condición industrial, además, resultó fertilmente

\footnotetext{
El nacimiento de plantas de metalurgia pesada y de otras industrias de base, sin embargo, no alcanzó a generar un más global ciclo de desarrollo autosostenido, a hacer detonar la revolución industrial a escala de las sociedades española o mexicana. Ni fue suficiente contar con modernizantes burguesías productoras ni, en el caso español,la industrialización global y autónoma pudo asegurarse sumando la precoz experiencia catalana.

'Véanse, por ejemplo, Fernández de Pinedo, 1974,1986, y 2001.
} 
estimulada desde 1841, cuando se trasladaron hacia esa frontera las aduanas que hasta entonces funcionaban en el interior del territorio español y, con ello, estimularon la renovación tecnológica de la siderurgia vizcaína y el surgimiento de otros sectores fabriles. No obstante, para los años 50 y 60, describe Fernández de Pinedo, "la burguesía bilbaína de más peso (seguía) siendo básicamente comercial y bancaria, con sus más firmes negocios vinculados al tránsito de mercancías y a las anejas necesidades crediticias". ${ }^{10}$ Este dinamismo mercantil - que en buena medida se nutría con los resabios del imperio colonial (Cuba y Puerto Rico) - se intensificó con el advenimiento del librecambio propiciado por la revolución de 1868 .

Bilbao, bien conectado con el interior peninsular mediante el ferrocarril desde finales de los años 50, cumplía el papel que se le asignaba como puerto del norte español en el comercio internacional. Sus grandes comerciantes manejaban, también, el crédito: un dato que quedó en evidencia no sólo con la muy temprana fundación del Banco de Bilbao, en 1857, sino también con su paralela instrumentación al movimiento comercial.'

Monterrey también se convirtió desde mediados de siglo en un significativo nudo mercantil. El cambio de la línea fronteriza tras la guerra con Estados Unidos (1846/47) le asignaría - a través de Texas una clara función de intermediaria con el mercado internacional. Esta posición quedó consolidada en los años del gobernador Santiago Vidaurri (1855-1864), quien se caracterizó por habilitar y poner a su servicio las aduanas sobre el río Bravo,y porfijar aranceles drásticamente más liberales que el que promulgó en la ciudad de México, en 1856, el presidente Ignacio Comonfort.

Fernández de Pinedo, 1989, p. 215, y 2001.

Sudriá, 1985, pp. 258-59, y Fernández de Pinedo, 1986. Este último autor resumió así los procesos transitados desde mediados de siglo y hasta la década de los 70: "Poco después de finalizar la primera guerra carlista se dieron las condiciones para iniciar una nueva fase de crecimiento. Las aduanas se situaban en la costa y habían desaparecido las barreras entre el mercado vasco y el resto de la monarquía; en 1849 se autorizaba la exportación de mineral, hasta entonces prohibida; la supresión de mayorazgos y la desamortización civil y eclesiástica desbloqueaban una parte de los obstáculos a la movilización de la riqueza monetaria en las zonas rurales (...) Todas estas medidas, con el cambio de la coyuntura internacional en los inicios de los años cincuenta, favorecerán una fase de crecimiento (...) que pondrá la base al desarrollo que se producirá a partir de los ochenta. Pero ese crecimiento dejará de lado las zonas rurales y se centrará en el comercio y la industria". Fernández de Pinedo, 1984, p. 318. 
Las luchas civiles desatadas por las leyes de Reforma y la invasión francesa no sólo aumentaron la autonomía de este gobernador en el lejano noreste: crearon además imperiosas necesidades militares que, en buena medida, fueron financiadas por núcleos de comerciantes situados a ambos lados de la frontera. El préstamo y el abastecimiento de guerra fueron dos vetas usufructuadas con amplitud y presteza por la embrionariaburguesía de Monterrey, que recibió otro enorme impulso gracias a las demandas generadas por la guerra de Secesión en Estados Unidos (1861-1865).'

España y México, por entonces, se encontraban envueltos en la contienda desatada por los avances del liberalismo. Fue un conflicto que atravesó ambas sociedades durante gran parte del XIX, y que tendió a atenuarse sólo en los años 70. En España, precisamente, uno de los últimos estertores de las luchas civiles terminó con la segunda guerra carlista, en 1876. En México, orden y progreso despuntaron con el advenimiento de Porfirio Díaz, también en 1876. Un prolongado período de estabilidad llegaría con la Restauración y el porfiriato, que fusionaron en ambos casos los intereses de conservadores que admitían ciertos cambios con los de liberales que habían domado su radicalismo.

Fue desde esos años 70 que se agregaron con firmeza otras actividades a la mercantil y a los movimientos conexos de dinero. Una variante resultó la lenta aproximación a la producción, por vías diversas. ${ }^{13}$ Otra, el uso más diferenciado del préstamo, del dinero en manos burguesas. Una tercera, no desligada de las anteriores, la apropiación del suelo y del subsuelo. ${ }^{14}$

A medida que se asentaba la estabilidad interior, las demandas de un mercado interno en articulación - aunque lentamente - aumentaron.

Para lo acontecido en Monterrey, el noreste de México y Texas a partir de 1850 puede consultarse Cerutti, 1983,1984 y 1992; y Cerutti y González, 1993 y 1999. Una incipiente industrialización se percibía ya en las "provincias marítimas" del País Vasco (Vizcaya y Guipúzcoa) a partir del traslado de las aduanas a la costa, en 1841. La protección arancelaria frente a la competencia extranjera permitió este arranque, financiado con capitales procedentes del comercio y de la tierra (Fernández de Pinedo, 2001). La especialización industrial de partida en cada provincia se debió a la existencia de recursos naturales, mano de obra cualificada y/o una tradición manufacturera previa. Valdaliso, 2001.

Para Monterrey, Cerutti, 1992. Para el caso de Vizcaya y la minería, Escudero, 1998; la adquisición de fincas en el ensanche bilbaíno ha sido indicada por Valdaliso, 1993. Un grupo empresarial particularmente activo en estos dos sectores fue el Echevarrieta y Larrínaga (Díaz Morían 1996 y 1999). 
El ferrocarril, en los dos casos, multiplicó los intercambios entre distintos ámbitos regionales (y, en el caso de Bilbao, reforzó el papel de su puerto), movimiento que se habría de intensificar por una ascendente tendencia a la especialización en la producción regional. Al inaugurarse la década de los 80 , por otro lado, las demandas externas se harían sentir con vigor.

El arranque de la sustitución de importaciones en Vizcaya

La minería del hierro emergió en Vizcaya como un sector fundamental. Usufructuando los importantes yacimientos de esta provincia, el norte español se adelantó levemente - en este rubro - al mexicano, que debió aguardar hasta la segunda fracción de los 80 para una explotación más imperiosa del subsuelo.

La explotación del mineral de hierro vasco fue incentivada por las demandas inglesas y, en una proporción elevada, impulsada por capitales extranjeros, que necesitaban un mineral de la calidad del vizcaíno para producir acero Bessemer. Pero los propietarios autóctonos parecen haber obtenido, directa o indirectamente, una tajada cuantiosa. Familias como los Martínez Rivas, Ybarra, Chávarri, Gandarias o Echevarrieta y Larrínaga, concentraron considerables beneficios.

No obstante, más que por la reinversión de esos beneficios (menos importante de lo que se había indicado), ${ }^{15}$ el hecho de disponer de un mineral de excepcional calidad movió a algunos empresarios de la provincia a montar plantas siderúrgicas para producir lingote de hierro colado y acero Bessemer tanto para el mercado nacional como para el europeo (las primeras estimaciones de las exportaciones tendieron a magnificar su importancia relativa durante el decenio de 1880; en tanto que las revisiones últimas señalan que, entre 1880 y 1900 , las repre-

La tesis tradicional - que sostenía que la industrialización de la Vizcaya se había financiado con los beneficios de la exportación de mineral - arranca con los publicistas del empresariado minero de principios del siglo XX y fue popularizada por González Portilla, 1981. Investigaciones recientes permiten saber que los beneficios de la minería se dirigieron al propio sector y a la compra de inmuebles, y que la financiación de la industria y los servicios que surgieron en Vizcaya dependió de capitales procedentes del comercio, de la propiedad y de los beneficios de cada sector, reinvertidos.Véanse los detalles en Fernández de Pinedo, 1988 y 1989; Valdaliso 1988, 1991 y 1993; Escudero, 1988 y 1998;Torres, 1993; y Díaz Morlán, 1996 y 1999a. 
sentaron alrededor del 25 por 100 de la producción. El resto se consumía en el mercado español). ${ }^{16}$

El cambio técnico en la siderurgia y, en concreto, la difusión de los nuevos procedimientos para la fabricación de acero, fue el factor que explica la hegemonía vizcaína dentro del mercado español: desde finales del siglo XIX hasta la entrada en funcionamiento de una nueva acería en Sagunto (Valencia) en los años 20, Vizcaya proporcionó cerca del 70 por 100 de la producción de hierro dulce y acero de España.

Las plantas levantadas entre 1879 y 1882 fueron la San Francisco, Altos Hornos y Fábricas de Hierro y Acero de Bilbao, y la Compañía Anónima de Metalurgia y Construcciones La Vizcaya. Estas dos últimas - las más importantes - habrían de fusionarse en 1902 entre sí y con La Iberia (gestada en 1888) en Altos Hornos deVizcaya.Todas ellas mostraban una gran capacidad de producción y abastecían tanto el mercado nacional como una porción del europeo. El cierre de este último mercado - consecuencia de las políticas proteccionistas aplicadas desde finales de los años 80 - terminó de orientar a los siderúrgicos vizcaínos al mercado interior, y promovió la creación de empresas metalúrgicas y de construcciones metálicas y de maquinaria (la mayor parte de las cuales surgió en Vizcaya).

La entrada en vigor del arancel de 1891 respaldó la estrategia de los fabricantes vizcaínos, que en esta década introdujeron tecnología de punta (hornos Martin-Siemens) para producir los nuevos tipos de acero que se demandaban. La protección del mercado interior favoreció la puesta en práctica de acuerdos de colusión y la concentración empresarial en la industria siderúrgica, dominada, a partir de 1902, por Altos Hornos de Vizcaya. ${ }^{17}$

El fuerte desarrollo experimentado por la marina mercante bilbaína en el último cuarto del siglo XIX, que convirtió a Bilbao en el puerto de registro de algo más de la mitad de la flota mercante española, acabó impulsando el nacimiento de industrias y servicios auxiliares a la navegación. En particular cabe destacar la creación de astilleros y talleres de reparación de buques, localizados en la ría de Bilbao,

González Portilla, 1981; Bilbao, 1985,pp. 225-26;y Fraile, 1985. Las revisiones del papel de las exportaciones en Fernández de Pinedo, 1987, y Escudero, 1999.

Sobre este proceso, véase Fernández de Pinedo 1983 y 2001 . En numerosos casos la creación de sociedades metalúrgicas fue impulsada por los propios siderúrgicos, que se convirtieron en accionistas significativos y, con frecuencia, en consejeros de las nuevas empresas. Valdaliso, 1988.

Monterrey y Bilbao (1870-1914): empresariado, industria y desarrollo regional en la periferia | 55 
cerca de la fuente de demanda y de las acerías proveedoras de chapa. Hasta la I Guerra Mundial, la empresa más importante en este sector fue la Compañía Euskalduna de Construcción y Reparación de Buques, a la que se unió la Sociedad Española de Construcción Naval a partir de $1917 .{ }^{18}$

Vizcaya disponía de una oferta abundante de mineral de hierro, pero no contaba con carbón, al que tuvo que importar de otras regiones de España y, sobre todo, del extranjero. Esta dependencia energética explica la rápida difusión de la electricidad en la industria vizcaína, iniciada en los años 90 del siglo XIX. El proceso de electrificación en Vizcaya estuvo, desde fechas relativamente tempranas, protagonizado por una gran empresa, Hidroeléctrica Ibérica, fundada en 1901 con el respaldo financiero del Banco de Vizcaya (que controlará buena parte de las sociedades de generación y distribución de energía eléctrica en España en estos años). ${ }^{19}$

La industrialización de Vizcaya requirió de una infraestructura de transportes y de una red de comunicaciones que, una vez puestas en marcha, contribuyeron considerablemente al desenvolvimiento económico. La red ferroviaria, nucleada en torno a Bilbao, ya estaba completada a principios del siglo $\mathrm{XX}$, haciendo de esta provincia una de las regiones más densamente conectadas de Europa.A la altura de 1913, por ejemplo, la densidad de la red ferroviaria en Vizcaya, era de 25 kilómetros por cada $100 \mathrm{~km}^{2}$ y de 18 kilómetros por habitante, cifras superiores a las que presentaban en su conjunto países como España, Francia, Gran Bretaña y Alemania y sólo comparables a las de Bélgica. ${ }^{20}$ La demanda creciente de infraestructura y de edificaciones fabriles y residenciales tuvo, a su vez, efectos de arrastre sobre la construcción y la fabricación de materiales destinados a este uso.

Monterrey: del comercio a la industria pesada

En el norte centrooriental de México, también desde mediados de los 70 comienza a observarse una mayor proclividad a dirigir recursos, bienes y capitales a sectores productivos.

18 Valdaliso, 1991 y 1998.

19 Maluquer de Motes, 1985; Garrues, 1998.

20 Ormaechea, 1988. 
Un caso distinguible fue el de la comarca de La Laguna, productora de algodón. Los núcleos mercantiles residentes en Monterrey (y en otras ciudades del norte: Saltillo, Chihuahua, Durango) quedaron ampliamente involucrados en el desenvolvimiento de estas tierras bañadas aluvionalmente por el río Nazas, que desciende de la Sierra Madre Occidental. La habilitación de dinero y mercancías que ofrecían a los agricultores movilizó la explotación especializada para el consumo interior. En ciertos casos - los Madero, los Zambrano y los vascos Hernández/Mendirichaga - hubo participación directa en la producción.

De una u otra forma, el financiamiento provenía de las antiguas casas mercantiles: la instrumentación del dinero era una actividad paralela y permanente. La dinámica financiera de estos grandes comerciantes configuró de hecho un sistema pre bancario en el norte oriental, que no desaparecería con el advenimiento de las instituciones bancarias especializadas. Patricio Milmo, el asturiano Valentín Rivero, los ya citados hermanos Hernández, Evaristo Madero y el también vasco Francisco Armendaiz, entre otros, operaban este fecundo ámbito. ${ }^{2}$

La apropiación de tierras en escala importante fue otro matiz de estos años de transición entre la expulsión de los ejércitos franceses (1867) y el brote fabril de los 90. Hacia los 80, como sucedió en el País Vasco, comenzó a explotarse el subsuelo: el carbón, en especial en el estado de Coahuila, fue un claro ejemplo. Si bien la minería no impactó tan directamente sobre Monterrey como sucedió en Bilbao, atrajo también fuertes capitales regionales y extranjeros y provocó una gigantesca movilización de los intercambios en el norte mexicano. Cuando aparecieron las grandes plantas de fundición, una relevante porción de los capitales de Monterrey convergió también hacia la explotación minera.

El comercio legal e ilegal, el uso del préstamo, y la concentración de la tierra y del subsuelo habían estimulado un proceso formativo de recursos y capitales que remató en la última década del XIX con la aparición de la industria urbana. El formidable mercado que la segunda revolución industrial había gestado en Estados Unidos, la articulación y expansión del mercado interno, la estabilidad sociopolítica porfiriana con sus claras modificaciones institucionales, y una adecuada legislación — tanto en el nivel federal como en el provincial - diseñaron una coyuntura propicia que no dejó de ser aprovechada por el embrionario empresariado de Monterrey.

Cerutti, 1986; Cerutti y otros, 1999. 
dustrial. Esta conclusión provisional no sólo estimula el ejercicio comparativo: quizás obligue a intentar, a la par, un esfuerzo, analítico para diferenciar sociedades como España dentro de esa Europa Occidental que tanto encandiló a los latinoamericanistas, y distinguir economías como la de México dentro de una América Latina que casi siempre los apesadumbra.

No habría que descartar, en este contexto, la necesidad de revisar la generalizada concepción de que toda producción exportadora de materias primas a fines del XIX llevaba obligatoriamente el estigma del subdesarrollo. La repercusión interna de bases exportadoras ${ }^{24}$ como las que sacudieron porciones del norte español y como las que agitaron al gigantesco septentrión mexicano, hace pensar en procesos más complejos. La dimensión del mercado nacional en configuración y el particular influjo proveniente de áreas próximas en plena revolución industrial deben ser analizados de manera insistente y específica.

A la vez, el arranque del ciclo industrializante - apoyado por ramas de la producción liviana - y el surgimiento de bancos locales y demás sociedades que se registró en ambas ciudades estuvieron conectados con un dato inevitable de remarcar: la instauración de un nuevo orden jurídico para el capital. La reorganización y afirmación de los respectivos códigos de comercio y la definitiva incorporación de la sociedad anónima a ese ordenjurídico resultaron un paso trascendental. Abrieron el camino para que los capitales acumulados por múltiples caminos se orientaran hacia rubros productivos evaluados como de alto riesgo, tanto por los montos de inversión como por su más lenta recuperación.

La sociedad anónima fue un sofisticado fruto del principio más general de responsabilidad limitada. Según ha detallado Tortella Casares, el opuesto y previo principio de "responsabilidad ilimitada" obligaba a cada asociado a responder "con todo su patrimonio" frente a las deudas contraídas por la sociedad inversionista. Ello suponía enormes riesgos para quien se animaba a participar en una empresa

\footnotetext{
${ }^{24}$ Fraile (1985) emplea el concepto base exportadora adoptado de autores como Harry Richardson y Richard Andrews. Aclara: "el concepto de 'base exportadora' es uno de los más usuales en análisis regional, y se basa fundamentalmente en la suposición de que el papel de la demanda externa es crucial en el desarrollo económico. La base exportadora comprende aquellas actividades orientadas al exterior de la región (...) Desarrollada por los geógrafos y urbanistas de los años cincuenta, la base exportadora es hoy uno de los instrumentos más comunes de la economía regional" (p. 227, nota al pie).
} 
mercantil o industrial de carácter comunitario. Por el contrario, el principio de responsabilidad limitada permitió fijar un máximo de pérdida por asociado: exactamente el que sumaba su aportación a la sociedad. "El elemento de riesgo — termina Tortella — queda así claramente limitado; la condición de socio de una empresa deja ya de ser una espada de Damocles sobre el patrimonio de aquél"..s

La forma más perfeccionada de las sociedades con responsabilidad limitada es la sociedad anónima: su capital se encuentra dividido en acciones que inclusive pueden venderse, transferirse. Gracias a esas características, la sociedad anónima facilitó la centralización de capitales dispersos para un fin común: objetivo que, de paso, era procurado por una sola dirección gerencial y permitía al socio situarse al margen de los desvelos cotidianos. El tratadista mexicano Ignacio Garfias Galindo ha indicado, por su lado, que el sistema capitalista encontró en la sociedad anónima no solamente un amplio campo de desarrollo:

"(...) dentro de este sistema económico ha sido el instrumento eficaz de que se ha servido el capitalismo para cumplir sus propios fines, proveyendo de una estructurajurídica a la grande industria y al comercio nacional e internacional (...) En verdad, este sistema económico busca por una parte la concentración de capitales en función de la producción industrial y del desarrollo del comercio; por otra parte, el capitalismo precisa de una rápida y flexible movilización de la riqueza (el dinero y el crédito) y finalmente el sistema capitalista ha demandado la distribución de los riesgos que gravitan sobre la empresa mercantil". ${ }^{26}$

\section{Sociedades empresariales y mercado de capitales en Bilbao y Monterrey}

Tortella analizó la evolución del marco jurídico de la sociedad anónima en España. Si bien ya se encuentran referencias en el código de comercio de 1829, fue recién hasta 1869 cuando se le otorgó la amplitudjurídica suficiente para tornarlo eficaz. Con la ley de 1869 que se promulgó en el contexto de la revolución liberal de 1868 - se alcanzó en España la posibilidad "de organizar sin trabas una sociedad por acciones o, lo que es lo mismo, se generaliza el principio de la

${ }^{25}$ Tortella Casares, 1968,pp. $70-71$.

${ }^{26}$ Garfias Galindo, 1957, pp. 8 y 9.

Monterrey y Bilbao (1870-1914): empresariado, industria y desarrollo regional en la periferia |61 
1899: Banco Mercantil de Monterrey), de compañías de transporte urbano y suburbano, de firmas en el área de servicios y en centenares de sociedades mineras. ${ }^{32}$ Unicamente el sector comercial continuó en manos de núcleos familiares aislados, siguiendo con ello las antiguas formas de organización provenientes de mediados del XIX.

Entre 1890 y las vísperas de la revolución de 1910 - dejando de lado el denso rubro minero y sin contar el comercial - miembros de las principales familias locales se integraron en alrededor de cien sociedades anónimas dedicadas a actividades diversas. En esos años encontramos que la familia Zambrano (mexicana) tenía acciones o vínculos con más de sesenta compañías. Francisco Armendaiz - entre 1890 y 1901 , año en que falleció - en 56. Un número análogo presentaban los Madero, encabezados por el patriarca Evaristo, uno de los épicos protagonistas de la fase de acumulación previa. Las cifras se ampliarían de manera rotunda si agregáramos — como se efectuó en Bilbao — otros núcleos familiares no tenidos en cuenta en la investigación y las sociedades configuradas por capitales extranjeros, sobre todo estadounidenses.

La articulación empresarial quedó sólidamente consumada en ambos escenarios urbanos con uniones de tipo matrimonial, con combinaciones familiares. En Bilbao, las décadas intermedias y finales del siglo XIX observaron la constitución y consolidación de núcleos parentales que llegaron a mantener un férreo control sobre la propiedad y la gestión de las empresas. Uno de los mecanismos utilizados, precisamente, fue vincular los descendientes a los órganos de decisión, asegurar el relevo futuro y configurar un capitalismo familiar en el que los puestos en los consejos de Administración se transferían de padres a hijos o de tíos a sobrinos. Si la promoción de los descendientes era un mecanismo fundamental de reproducción hegemónica en la capital vizcaína, no lo era menos el matrimonio, el nexo marital entre miembros de las diferentes familias. La alta burguesía local estableció además ámbitos exclusivos de sociabilidad (colegios, clubes, áreas residenciales) que reforzaron una política matrimonial marcadamente endogámica. ${ }^{33}$

Cerutti, 1992.

Al menos una tercera parte de los consejeros de los tres grandes bancos bilbaínos a principios de siglo XX (Banco de Bilbao, Banco de Vizcaya, Banco de Crédito) tenían alguna relación de parentesco entre si.Valdaliso, 1994,pp. 18-19. Para algunos ejemplos concretos véanse los trabajos de Torres, 1998, sobre los Sota, o de Díaz Morlán, 1999b, sobre los Ybarra. 
Sociedad anónima, redes familiares y mecanismos matrimoniales se complementaron de manera evidente, también, en el Monterrey que se desenvuelve desde los 90, década en la cual empieza a engrosarse el tronco de lo que en el siglo XX sería un poderoso empresariado regional. Miembros de los grupos parentales indagados participaron conjuntamente o predominaron en decenas de sociedades, cuarenta de las cuales sumaban capitales de arranque que oscilaban entre los 50 mil y los cinco millones de dólares. Las mujeres, por su lado, debieron ser tenidas en cuenta en el análisis de los orígenes (y perdurabilidad) de este empresariado. Aun cuando casi no pertenecían a los cuadros directivos, era evidente su funcionalidad al ser incorporadas a matrimonios que entrelazaban o conectaban núcleos familiares de relevancia en el mundo del capital. ${ }^{34}$

\section{Lazos interregionales}

Tanto en Bilbao como en la mexicana Monterrey la sociedad anónima y los lazos familiares posibilitaron unir no sólo capitales del entorno inmediato. Facilitaron, asimismo, la centralización de capitales procedentes de diversos focos territoriales de crecimiento económico en los respectivos estados nacionales.

En Bilbao, una parte significativa del capital invertido en las tres grandes plantas siderúrgicas montadas a principios del decenio de 1880 fue aportado por grupos empresariales con sede en Madrid y Barcelona, con una participación menor de casas mercantiles de origen vizcaíno domiciliadas en Londres y Liverpool. ${ }^{35}$ El capital inglés también desempeñó un papel importante en la financiación de las primeras grandes compañías navieras vizcaínas constituidas en los decenios de 1870 y 1880 (sector donde la presencia de capitales de otras partes de España era, por el contrario, muy reducida). ${ }^{36}$

Pero la actividad que atrajo más capitales extranjeros (de Inglaterra, Francia y Bélgica, fundamentalmente) fue la minería del hierro, montando filiales de grandes grupos minero-siderúrgicos y, a veces, en colaboración con familias como los Ybarra. ${ }^{37}$ Otro aporte signifi-

${ }^{34}$ Cerutti, 1992 y 2000 , Saragoza, 1988.

${ }_{35}$ Fernández de Pinedo, 1988,pp. 258-73,y 1989, p. 224.Las casas mercantiles domiciliadas en el Reino Unido eran Cristóbal de Murrieta y Cía. y Olano, Larrínaga y Cía.

${ }^{36}$ Valdaliso, 1991, pp. 203-216.

Escudero, 1998, y Díaz Morían, 1999b.

Monterrey y Bilbao (1870-1914): empresariado, industria y desarrollo regional en la periferia | 65 
cativo de capitales procedió de los «indianos», emigrantes vizcaínos que se enriquecieron en México, Cuba o Argentina y que retornaron a Bilbao en la coyuntura finisecular. ${ }^{3 *}$

La información obtenida en el Registro Mercantil permite identificar con frecuencia los orígenes geográficos de los inversionistas. De las sociedades mercantiles creadas en Vizcaya entre 1879 y 1913 , el 4.8 por ciento era de Santander, el 4.3 de Madrid y el 4.9 del resto de España. Aunque el predominio de los procedentes del mismo Bilbao (64.9 por ciento) era notorio, las cifras indicadas demuestran la capacidad de la ciudad para atraer capitales de otros centros de actividad españoles. Se sabe asimismo que los capitales manejados desde Bilbao efectuaron numerosas inversiones en otros espacios regionales. Al igual que en la minería del hierro y el carbón, Bilbao se convirtió en domicilio de un amplio número de sociedades eléctricas que explotaban saltos de agua en otras zonas de España. Los intereses de la burguesía vizcaína desbordaban claramente los límites regionales y se extendían por todo el país (Asturias fue uno de los ejemplos más llamativos). ${ }^{39}$

La sociedad anónima facilitó un tipo análogo de comportamiento en Monterrey. Casos llamativos fueron los del Banco Mercantil y la Compañía Carbonífera de Monterrey, en las que sobresalía la participación de Enrique C. Creel, ilustre miembro del grupo de los Terrazas de Chihuahua y uno de los financistas más relevantes del porfiriato. Repetidos asociados en firmas locales eran personajes como Joaquín Casasús - figura descollante de la política y los negocios en la ciudad de México - Marcelino Garza y José Negrete, con residencia en Saltillo.

Esta imbricación de capitales regionales hizo emerger en el norte de México otro importante nudo de inversiones: la ya mencionada comarca algodonera de La Laguna. Tanto el desarrollo del cultivo de la fibra como gran parte del desenvolvimiento bancario, agroindustrial y fabril de La Laguna germinó gracias a la asociación de capitales regionales, muchos de ellos procedentes de Monterrey y de la norteña Chihuahua. Esto coadyuvó a que se articulara en vísperas de la revolución de 1910 un eje empresarial que bajaba desde Chihuahua, cruzaba la propia Laguna y remataba en Monterrey. Proyectos conjuntos de familias chihuahuenses, laguneras y regiomontanas fueron, entre otros, La Esperanza (1887) y

\footnotetext{
${ }^{38}$ Valdaliso, 1993. Sobre la actividad de algunos de estos indianos en México, véase Cerutti, 1995. Sobre sus negocios en Vizcaya, Valdaliso, en prensa.

${ }^{39}$ Valdaliso, 1993.
} 
su sucesora, la Compañía Industrial de La Laguna Jabonera (1892); Cementos Hidalgo (1906, hoy convertida en CEMEX, la tercera cementera del mundo); Banco Refaccionario de La Laguna (1907); Banco Mercantil de Monterrey (1899); y Vidriera Monterrey (1909).

Como sucedió en Bilbao, las nuevas y grandes inversiones solían exigir la vinculación con capitales extranjeros (o no regionales) o sus representantes. Un ejemplo en tal sentido lo fue la Compañía Fundidora de Fierro y Acero de Monterrey, cuya escritura constitutiva se rubricó en mayo de 1900. Ante el monto de la inversión inaugural no puede extrañar que - por medio de la sociedad anónima - se anotase en el proyecto apellidos como Armendaiz, Belden, Calderón-Muguerza, Hernández-Mendirichaga, Ferrara, Madero, Milmo, Maiz, Kelly, Rivera, Sada Muguerza, Garza y Zambrano (grupos parentales especialmente investigados), sino también Tárnava,Bortoni, González Treviño,Dresel, Villarreal, Cantú Treviño. Al lado de ellos, Tomas Braniff, de origen estadounidense; los franceses Leon Signoret y Leon Honnorat; y el prominente vasco Antonio Basagoiti."

\section{Transferencia de tecnología y de capital humano}

Los empresarios de Bilbao y Monterrey canalizaron capitales de otras regiones y del extranjero. Pero tan importante como lo anterior fue que también tuvieron amplias oportunidades (e interés) de acceder a tecnología y capital humano de los principales núcleos del desarrollo económico: Inglaterra, Francia, Bélgica y Alemania en el caso bilbaíno; los Estados Unidos en el caso regiomontano. La transferencia de tecnología no se realizó simplemente a través de la importación de maquinaria y equipos: supuso simultáneamente la llegada de técnicos - ingenieros y personal calificado - encargados de manejarla y de adiestrar la mano de obra autóctona.

En Bilbao los ingenieros constituyeron el tercer grupo de inversores entre 1879 y 1913 , por detrás de los comerciantes y los propietarios. Algo más de la mitad habían nacido en la provincia, estudiando en Madrid o en el extranjero y retornaron después a la provincia como

\footnotetext{
${ }^{40}$ El entrelazamiento de capitales en la comarca de La Laguna (compartida por los estados de Coahuila y Durango) puede verse en Barragán y Cerutti, 1993, y Cerutti, 1994.

"Archivo General del Estado de Nuevo León, protocolo de Tomás C. Pacheco, 5 de mayo de 1900, fs. 392-415.
}

Monterrey y Bilbao (1870-1914): empresariado, industria y desarrollo regional en la periferia |67 
empresarios o directivos de las nuevas empresas. El resto procedía de otras partes de España o bien del extranjero y llegaron a Bilbao en el último cuarto del siglo XIX para cubrir la demanda de técnicos y directivos. ${ }^{42}$ La demanda de las empresas acabó impulsando la creación de centros de enseñanza superior: a las ya existentes Escuelas de Náutica y de Comercio, se añadieron la Escuela Superior de Ingenieros Industriales, que comenzó a impartir clases en 1899, y una Universidad Comercial (vinculada con los jesuitas, Universidad de Deusto), desde 1916 en adelante. ${ }^{43}$

En Monterrey, como en buena parte del noreste de México, la conexión con la economía de los Estados Unidos se tornó un dato normal desde 1850. Sus comerciantes se habían entrelazado y/o competido con los que operaban desde Texas ya en tiempos de la guerra de Secesión (1861-1865). Cuando llegó la reconstrucción postbélica a ambos lados de la frontera (tras el ciclo de guerras intestinas e internacionales), los capitales texanos se desplazaron casi de inmediato hacia el noreste, en especial en el sector minero, y se asociaron en más de una ocasión con los propietarios locales.

No puede sorprender que al arribar el ferrocarril e iniciarse el brote fabril en Monterrey sus empresarios estuvieran muy pendientes del cambio tecnológico que protagonizaba uno de los escenarios fundamentales de la segunda revolución industrial. Los viajes a centros tan reconocidos como Nueva York, Pittsburgh, San Luis Missouri o Chicago solían ser frecuentes, y han quedado documentados con amplitud. Empresas como Vidriera de Monterrey (que monopolizó en México la patente Owens para la fabricación automática de envases de vidrio ${ }^{44}$ ), Cementos Hidalgo o las grandes fundiciones importaban de Estados Unidos tanto equipos como supervisores calificados para la conducción técnica de las plantas y para el adiestramiento de la mano de obra. También se introdujeron de Estados Unidos experiencias sobre organización empresarial, la gestión y las formas de atacar los mercados.

Pero una influencia que habría de tener enorme repercusión fue la recibida en centros de estudios como el Instituto Tecnológico de Massachussetts (MIT, por sus siglas en inglés). Hasta allí fueron enviados

${ }^{42}$ Valdaliso, 1993. La información sobre los ingenieros procede de las fuentes citadas en Valdaliso, 1993.

43 Ibídem, 2001 . La formación de la mano de obra, por el contrario, siguió realizándose, sobre todo, dentro de las propias empresas, véase Pérez Castroviejo, 1992.

${ }^{44}$ Barragán, 1993; Barragán y Cerutti, 1993. 
desde principios del siglo XX los miembros de una generación que habría de reemplazar a los fundadores. Casos muy reconocidos son los de Roberto. Sada y Eugenio Garza Sada, quienes tras llegar de Estados Unidos se insertaron en la empresa cervecera y en la productora de vidrio que habían fundado sus parientes más cercanos y luego - ya en los años 30 - las convirtieron en auténticos emporios industriales. Mas aún, el propio Eugenio Garza Sada terminaría fundando en 1943 el Instituto Tecnológico y de Estudios Superiores de Monterrey, que se creó como una reproducción del MIT y que se habría de transformar en una verdadera fábrica de cuadros gerenciales y técnicos. La americanización de Monterrey, en este sentido, se anticipó a lo que sucedería en no pocas urbes de la Europa durante la Segunda Posguerra.

\section{Algunas diferencias y breve recuento final}

Si bien son numerosas las similitudes y los posibles elementos cotejables entre Bilbao y Monterrey, corresponde indicar algunas diferencias sustantivas.

La primera fue que mientras Monterrey (como otros puntos del norte mexicano) fue receptora de inmigrantes españoles que se convirtieron en empresarios - una parte de los cuales provenía deVizcaya ${ }^{45}$ Bilbao recibió gruesos capitales transferidos por vizcaínos enriquecidos en América (los indianos), algunos de ellos del norte de México y de la propia Monterrey. ${ }^{46}$

La segunda diferencia es de carácter geográfico: Bilbao estuvo marcada desde el punto de vista de su historia económica por su condición de puerto marítimo y fluvial, en tanto Monterrey dependió de puertos marítimos mexicanos y estadounidenses para sus contactos comerciales; Monterrey, por su condición interior, por su localización geográfica y por las características del sistema de ferrocarriles que se prolongaba desde los Estados Unidos, fue un importante nudo de comunicaciones ferroviarias, en tanto que Bilbao presentó - en ese sentido - una posición menos central.

La tercera distinción derivó con frecuencia de las diferentes coyunturas políticas internacionales y nacionales. Un nítido ejemplo fue cómo Bilbao (ayudado por su localización y por su condición portuaria) aprovechó las necesidades generadas por la primera Guerra, mientras que

\footnotetext{
${ }^{45}$ Cerutti, 1995 y 1999.

${ }^{46}$ Valdaliso, 1993.
}

Monterrey y Bilbao (1870-1914): empresariado, industria y desarrollo regional en la periferia | 69 
Monterrey (como gran parte de México) no pudo usufructuar la coyuntura bélica debido a la revolución que estalló en 1910.

El ejercicio efectuado en este suscinto trabajo, por cierto, no pretende agotarse en los apartados estudiados. Líneas de trabajo no exploradas aún de manera detallada podrían incluir, verbigracia, los indicadores demográficos y los de cambio estructural. Dado que tanto Bilbao como Monterrey demandaron un volumen de mano de obra que excedía las disponibilidades existentes en sus propios entornos, queda por ver la intensidad y radio de procedencia del caudal migratorio que nutrió el desarrollo industrial. Y las transformaciones que el mismo proceso de industrialización introdujo en la estructura ocupacional de la población activa, en la de sus flujos comerciales o en el PIB regional pueden ser motivo de nuevos ejercicios de comparación.

Y aunque se han adelantado ya algunas conclusiones, nos permitiremos complementarlas con este recuento final.

1. Resulta prioritario insistir en las posibilidades que abrieron para Bilbao y Monterrey (para sus empresarios) las demandas cruzadas de dos mercados: las generadas en una economía nacional de ritmos relativamente lentos, y las provenientes de economías avanzadas (más vivas) que resultaban particularmente accesibles por su cercanía. Tal vez por ello convenga dejar de desdeñar el impacto que sobre los respectivos mercados internos y sobre los sistemas productivos regionales mantuvieron las actividades exportadoras. Tanto las demandas de materias primas que se mercantilizaba desde sus aledaños - y que abrían conductos para la acumulación de capitales - como la demanda directa de insumos industriales - hierro, acero, plomo, cobre - asumieron significación en el crecimiento económico regional.

2. Conviene reiterar, de todos modos, que en economías periféricas de mayor desarrollo (como las aquí consideradas), el mercado nacional en constitución supuso una influencia que no puede ni debe desconocerse. Que dicho mercado fuese débil, si se lo compara con el de las sociedades que protagonizaban la revolución industrial, no cambia demasiado las cosas. El caso español evidencia, por otro lado, que esa debilidad o lentitud no era una exclusividad latinoamericana.

3. Hay que insistir en la importancia de la aparición de grandes plantas productoras de insumos industriales. La experiencia empresarial motivada inicialmente por el mercado externo - experiencia anticipada en ambos casos por la actividad mercantil - derivó con frecuencia en inversiones que también aprovecharon el desenvolvimiento de un mercado interior. En Monterrey, verbigracia, la instalación de la siderur- 
gia pesada fue consecuencia, entre otras cosas, del entrenamiento adquirido durante una década de labor en el procesamiento de metales industriales destinados al este norteamericano.

4. En los dos casos la transferencia de tecnología, de técnicas específicas, de métodos de organización y gestión y de capital humano se veía facilitada por el contacto - muchas veces personal — con ciudades o lugares que eran ejes de la revolución industrial. Esta faceta se habría de enriquecer cuando una nueva generación - que asume la dirección de las empresas en los años 20 - se instruye en establecimientos de enseñanza especializados de esos mismos países avanzados.

5. Otra arista cotejable entre Bilbao y Monterrey es la que alude a la insuficiencia de sus procesos de industrialización para transformar globalmente la estructura económica de los estados-nación a los que pertenecían. Aunque embarcadas en un desenvolvimiento fabril no detectable con facilidad en buena parte del mundo periférico, no alcanzaron a propiciar una división interna de la producción suficientemente vigorosa como para integrar a España y México al más selecto grupo del universo capitalista. El atraso en la agricultura y la limitadísima evolución del sector dedicado a la producción de bienes y equipos lo demostrarían. Producir acero o montar un astillero no era suficiente en momentos en que el motor a combustión, la química de alta complejidad, la electricidad y la producción en gran escala de maquinaria - entre otros rubros concitaban el advenimiento de la llamada segunda revolución industrial.

\section{Referencias bibliográficas}

Barragán,Juan Ignacio. "Empresarios del norte e importación de tecnología a principios del siglo XX". En: Siglo XIX. Cuadernos de Historia, 6,junio, 1993.

Barragán, Juan Ignacio y Cerutti, Mario.Juan F. Brittingham y la industria en México, 1859-1940, Monterrey: Urbis Internacional, 1993.

Bilbao y Bilbao, Luis María. "Renovación tecnológica y estructura del sector siderúrgico en el País Vasco durante la primera etapa de industrialización (1849-1880).Aproximación comparativa con la industria algodonera de Cataluña". En: Portilla, Manuel González, Motes, Jordi Maluquer de y Permanyer, Borja de Riquer (Eds.). Industrialización y nacionalismo. Análisis comparativos, Barcelona: Universidad Autónoma de Barcelona, 1985.

Carreras de Odriozola,Albert."La producción industrial catalana y vasca, 1844-1935. Elementos para una comparación". En: Industrialización y nacionalismo, citado. 1985.

Castronovo,Valerio,"Industria y burguesía en el norte de Italia". En: Cerutti, Mario y Vellinga, Menno (Comps.). Burguesías e industria en América Latina y Europa meridional. Madrid: Alianza Editorial, 1989. 
Cerutti, Mario. Economía de guerra y poder regional en el siglo XIX, Monterrey, Archivo General del Estado de Nuevo León, 1983.

Cerutti, Mario."Aduanas, poder regional y Estado Nacional, en México a mediados del siglo XIX". En: Trienio. Ilustración y liberalismo, 4, noviembre, 1984.

Cerutti, Mario. "División capitalista de la producción, industrias y mercado interior. Un estudio regional: Monterrey (1890-1910)". En: Cerutti, Mario (Coord.), El siglo XIX en México. Cinco procesos regionales, México: Claves Latinoamericanas, 1985.

Cerutti, Mario. "El préstamo prebancario en el noreste de México. La actividad de los grandes comerciantes de Monterrey (1855-1890)". En: Ludlow, Leonor y Marichal, Carlos (Eds.). Banca y poder en México (1800-1925). México: Enlace-Grijalbo, 1986.

Cerutti, Mario. Burguesía, capitales e industria en el norte de México. Monterrey y su ámbito regional (1850-1910). México:Alianza Editorial/Universidad Autónoma de Nuevo León, 1992.

Cerutti, Mario."Empresarios y sociedades empresariales en el norte de México (18701920)". En: Revista de Historia Industrial, 4, 1994.

Cerutti, Mario. Empresarios españoles y sociedad capitalista en México (1840-1920), Colombres, Archivo de Indianos, 1995.

Cerutti, Mario."Propietarios y empresarios españoles en La Laguna (1870-1910)". En: Historia Mexicana, vol. XLVIII, 4, abril junio, 1999.

Cerutti, Mario. El norte de México y Texas (1848-1880). Comercio, capitales y trabajadores en una economía de frontera. México: Instituto de Investigaciones Dr. Mora, 1999.

Cerutti, Mario. Propietarios, empresarios y empresa en el norte de México. México: Siglo XXI Editores, 2000 .

Cerutti, Mario y Vellinga, Menno (Comps.). Burguesía e industria en América Latina y Europa meridional. Madrid, Alianza Editorial, 1989.

Cerutti, Mario y Quiroga, Miguel González (Comps.). Frontera e Historia Económica. Texas y el norte de México (1850-1865),.México, Instituto de Investigaciones Dr.Mora/ Universidad Autónoma Metropolitana, 1992.

Cerutti, Mario, Páez, Sergio Corona y García, Roberto Martínez. Vascos, agricultura y empresa en México, México: Porrúa/Universidad Iberoamericana. 1999.

Chandler Jr, Alfred D. Escala y diversificación. La dinámica del capitalismo industrial. Zaragoza: Prensas Univerzitarias de Zaragoza, 1996.

Díaz Morlán, Pablo. "Capital minero e industrialización. El grupo empresarial vizcaíno 'Echevarrieta y Larrínaga' (1882-1916)", Revista de Historia Industrial, 9,1999a, p. 153-173.

Díaz Morlán, Pablo. Horacio Echevarrieta, el capitalista republicano. Madrid: LID. 1999a.

Díaz Morlán, Pablo. "Los Ybarra vizcaínos. Orígenes y expansión de una saga familiar (1801-1890)". Madrid: Fundación Empresa Pública/Programa de Historia Económica, Documento de Trabajo 9908,1996b.

Escudero,Antonio."La minería vizcaína durante la primera guerra mundial".En: Revista de Historia Económica.V. IV, 2,1984, pp. 365-387.

Escudero, Antonio."Minería e industrialización en Vizcaya: objecciones a una teoría tradicional". En: Pinedo, Fernández de y Marco,José Luis Henrández (Eds.). La industrialización en el norte de España. Barcelona: Universidad del País Vasco-Crítica, 1988. 
Escudero, Antonio. Minería e industrialización de Vizcaya. Barcelona: Crítica, 1998.

Escudero, Antonio. "Dos puntualizaciones sobre la historia de la siderurgia española entre 1880 y 1930". Revista de Historia Industrial, 15, 1999, p. 191-200.

Fernández de Pinedo, Emiliano. Crecimiento económico y transformaciones sociales del País Vasco (1100-1850). Madrid: Siglo XXI, 1974.

Fernández de Pinedo, Emiliano. "Nacimiento y consolidación de la moderna siderurgia vasca (1849-1913). El caso de Vizcaya". En: Información Comercial española, 598. Junio, 1983.

Fernández de Pinedo, Emiliano. "Etapas del crecimiento de la economía vasca (17001850)". En Papeles de la economía española, 20, 1984.

Fernández de Pinedo,Emiliano."El desarrollo de Bilbao y sus actividades (1300-1936)". En Exposición Centenario (1886-1986). Bilbao: Cámara de Comercio, Industria y Navegación de Bilbao, 1986.

Fernández de Pinedo, Emiliano. "Factores técnicos y económicos en el origen de la moderna siderurgia y la flota vizcaína, 1880-1899". En: Pinedo, Fernández de y Marco, José Luis Henrández (Eds.). La industrialización en el norte de España. Barcelona: Universidad del País Vasco-Crítica, 1988.

Fernández de Pinedo, Emiliano. "Burguesía comercial autóctona, proteccionismo e industrialización en el País Vasco en el siglo XIX". En: Cerutti y Vellinga, Burguesías e industria, citado, 1989.

Fernández de Pinedo, Emiliano. "De la primera industrialización a la reconversión industrial: la economía vasca entre 1841 y 1990". En: Germán, Luis y otros. Historia económica regional de España, Siglos XIX y XX. Barcelona: Crítica, 2000.

Fraile Balbín, Pedro. "La periferia siderometalúrgica europea. Una nota histórica sobre el País Vasco". En: Información Comercial Española, 591. Noviembre, 1982.

Fernández de Pinedo, Emiliano. "El País Vasco y el mercado mundial, 1900-1930". En: Sánchez-Albornoz,Nicolás (Comp.).La modernización económica de España. 1830-1930. Madrid: Alianza Editorial, 1985.

Garfias Galindo, Ignacio. Sociedad Anónima. Responsabilidad civil en los administradores. México: Imprenta Nuevo Mundo, 1957.

Garrués Irurzun, Josean. Empresas y empresarios en Navarra. La industria eléctrica, 18881986. Pamplona: Gobierno de Navarra-Depto. Educación y Cultura. 1997.

González Portilla, Manuel. Laformación de la sociedad capitalista en el País Vasco (18761913). San Sebastián: L. Haramburu Editor AS, 1981.

Harrison, Joseph. "Los orígenes del industrialismo moderno en el País Vasco, 1876 1936". En: Información Comercial Española, 55. 1978.

Harrison, Joseph. "La industria pesada, el Estado y el desarrollo económico en el País Vasco, 1876-1936". En: Información Comercial Española, 598. 1983.

Maluquer de Motes, Jordi. "Cataluña y el País Vasco en la industria eléctrica española". En: Industrialización y nacionalismo, citado, 1985.

Maluquer de Motes,Jordi."Una economía de frontera con el norte europeo. El desarrollo de Cataluña en los siglos XVII al XX". Ponencia presentada en el V Congreso de Historia Económica de Brasil, Sao Paulo, septiembre, 2001. 
Menegus, Margarita y Cerutti, Mario. (Coords., en prensa), La desamortización civil en México y España (1780-1920). Monterrey: Universidad Autónoma de Nuevo León.

Nadal, Jordi. El fracaso de la Revolución Industrial en España, 1814-1913. Barcelona: Ariel, 1991.

Ormaechea Hernaiz, Angel $\mathrm{M}^{2}$. Ferrocarriles en Euskadi, 1855-1936. Bilbao: Eusko Trenbideak, 1989.

Pérez Castroviejo, Pedro. Clase obrera y niveles de vida en las primeras jases de la industrialización vizcaína. Madrid: Ministerio de Trabajo y Seguridad Social, 1992.

Philipp,Walter Frisch. La sociedad anónima. México: Porrúa, 1952.

Pollard, Sidney. La conquista pacífica. La industrialización de Europa, 1760-1910. Zaragoza: Universidad de Zaragoza, 1991.

Saragoza,Alex. The Monterrey Elite and the Mexican State, 1880-1940. Austin,University of Texas Press, 1988 .

Sudriá i Triay, Carles. "Formas de industrialización y desarrollo bancario en Cataluña y Euskadi (1840-1936)". En: Industrialización y nacionalismo, citado, 1985.

Torres, Eugenio."Barcos, carbón y mineral de hierro. Los vapores de Sota y Aznar y los orígenes de la moderna flota mercante de Bilbao, 1889-1900", Revista de Historia Económica, IX, 1, 1991.

Torres, Eugenio. Ramón de la Sota, un empresario vasco (1851-1936). Madrid: LID, 1998.

Tortella Casares, Gabriel. "El principio de responsabilidad limitada y el desarrollo industrial de España: 1829-1869". En: Moneda y Crédito, 104, marzo, 1968.

Valdaliso, Jesús María. "Grupos empresariales e inversión de capital en Vizcaya, 1886 1913", Revista de Historia Económica,Vl, 1, 1-30, 1988.

Valdaliso,Jesús María. "Política económica y grupos de presión. La acción colectiva de la Asociación de Navieros de Bilbao, 1900-1936". Historia Social,7, 1990.

Valdaliso,Jesús María. Los navieros vascos y la marina mercante en España, 1860-1935. Una historia económica. Bilbao: IVAP, 1991.

Valdaliso, Jesús María. "Los orígenes del capital invertido, en la industrialización de Vizcaya, 1879-1913". En Revista de Historia Industrial, 4, 1993.

Valdaliso, Jesús María. "De comerciantes y rentistas a empresarios e ingenieros. El ascenso de la burguesía industrial y financiera en Vizcaya (1880-1913)". Ponencia presentada a las XIV Jornadas de Historia Económica Argentina, Córdoba, mimeo, 1994.

Valdaliso,Jesús María. "Nacimiento y desarrollo de la industria naval del hierro y el acero en el País Vasco: el caso de Vizcaya (c1889-1979)". Itsas Memoria, 2,1998, pp. 307-325.

Valdaliso, Jesús María. "La industrialización en el primer tercio del siglo XIX y sus protagonistas", Bilbao. En: José Luis de la Granja (Dir.), Historia del País Vasco en el siglo $X X$. Barcelona: Ariel, en prensa.

Valdaliso, Jesús María."Comerciantes e industriales en México, banqueros e industriales en Vizcaya. Algunas notas sobre los indianos Aresti, López de Letona, Hernández Mendirichaga y Maíz". Illes e Imperis., en prensa.

\section{4 | Mario Cerutti \& Jesús María Valdaliso}

